\title{
Constraints on Target Chamber First Wall and Target Designs That Will Enable NIF Debris Shields to Survive
}

\author{
A. K. Burnham, M. Gerassimenko, \\ J. M. Scott, J. F. Latkowski, \\ P. K. Whitman, F. Y. Genin, \\ W. Hibbard, P. F. Peterson, \\ R. E. Tokheim, and D. R. Curran
}

This paper was prepared for submittal to the Third Annual International Conference on Solid State Lasers for Application (SSLA)

to Inertial Confinement Fusion (ICF)

Monterey, California

June 7 12, 1998

July 9, 1998

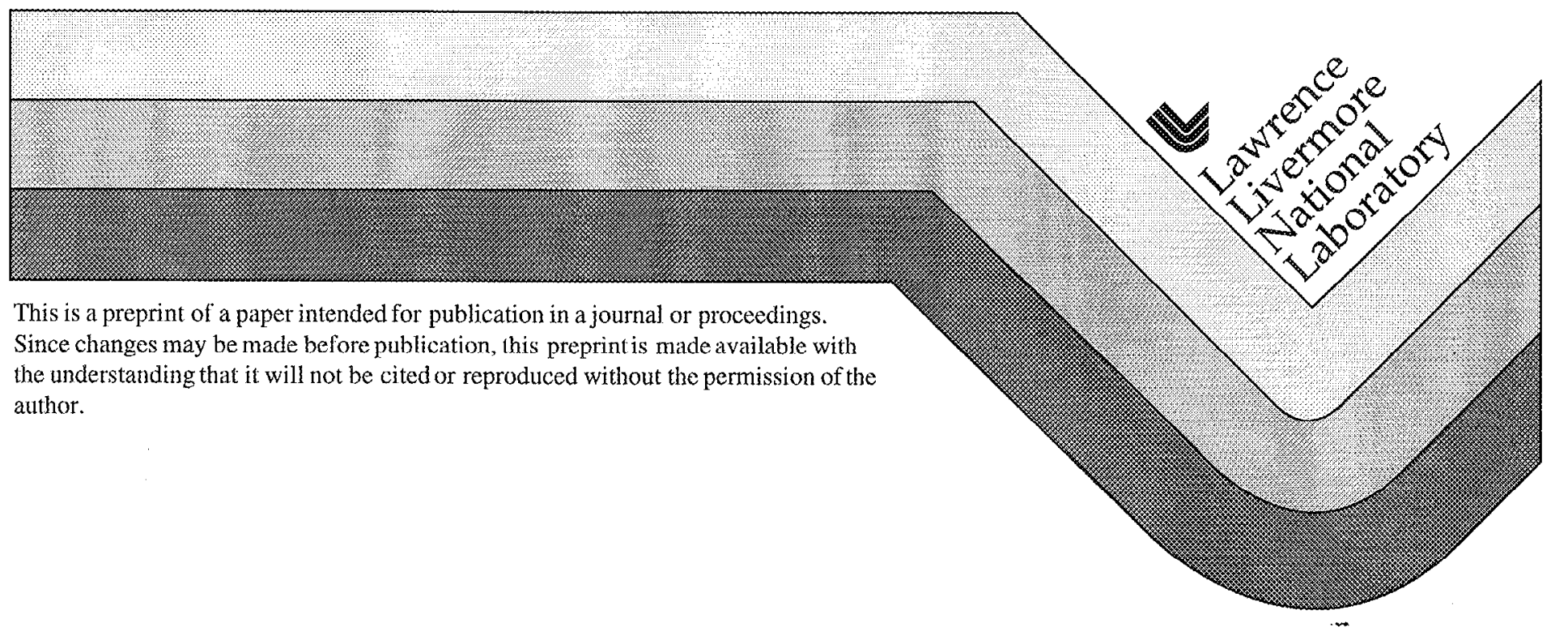




\section{DISCLAIMER}

This document was prepared as an account of work sponsored by an agency of the United States Government. Neither the United States Government nor the University of California nor any of their employees, makes any warranty, express or implied, or assumes any legal liability or responsibility for the accuracy, completeness, or usefulness of any information, apparatus, product, or process disclosed, or represents that its use would not infringe privately owned rights. Reference herein to any specific commercial product, process, or service by trade name, trademark, manufacturer, or otherwise, does not necessarily consitute or imply its endorsement, recommendation, or favoring by the United Stales Government or the University of California. The views and opinions of authors expressed herein do not necessarily state or reflect those of the United States Government or the University of California, and shall not be used for advertising or product endorsement purposes. 


\title{
Constraints on Target Chamber First Wall and Target Designs That Will Enable NIF Debris Shields To Survive
}

\author{
A. K. Burnham ${ }^{a}$, Michel Gerassimenko ${ }^{a}$, J. M. Scott ${ }^{b}$, J. F. Latkowski ${ }^{a}$, P. K. Whitman ${ }^{a}$, F. Y. Genin ${ }^{a}$,

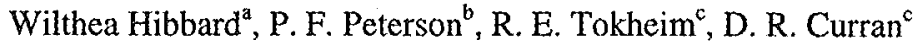 \\ alawrence Livermore National Laboratory, Livermore, CA 94551 \\ ${ }^{b}$ University of California, Berkeley, CA 94720

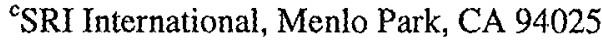

\begin{abstract}
The National Ignition Facility target chamber interior materials and target designs themselves have to be compatible with survival of the final-optics debris shields. To meet the planned maintenance and refinishing rate, the contamination of the debris shields cannot exceed about $1 \mathrm{~nm}$ equivalent thickness per shot of total material. This implies that the target mass must be limited to no more than 1 gram and the ablated mass released to the chamber from all other components must not exceed 3 grams. In addition, the targets themselves must either completely vaporize or send any minor amounts of shrapnel towards the chamber waist to prevent excessive cratering of the debris shields. The constraints on the first-wall ablation require that it be louvered to provide passive collection of remobilized contamination, because the expected target debris will remobilize at a rate fast enough to require cleaning every 3 weeks, about three times more frequent than possible with planned robotics. Furthermore, a comparison of ablatants from $\mathrm{B}_{4} \mathrm{C}$ and stainless-steel louvers suggests that remobilization of target debris by $x$ rays will be greater than of the base material in both cases, thereby reducing the performance advantage of clean $\mathrm{B}_{4} \mathrm{C}$ over much-cheaper stainless steel. Neutronics calculations indicate that activation of thin Ni-free stainless steel is not a significant source of maintenance personnel radiation dose. Consequently, the most attractive first wall design consists of stainless-steel louvers. Evaluation of various unconverted-light beam dump designs indicates that stainless steel louvers generate no more debris than other materials, so one single design can serve as both first wall and beam dumps, eliminating beam steering restrictions caused by size and location of the beam dumps. One reservation is that the allowable contamination rate of the debris shield is not yet completely understood. Consequently, it is likely that either a protruding beam tube, a rapid post-shot gas purge of the final optics assembly, or thin polymeric pre-shield will be required to prevent low-velocity contamination from reaching the debris shield.
\end{abstract}

Keywords: $x$-ray ablation, National Ignition Facility, boron carbide, 409 stainless steel, laser beam dumps

\section{INTRODUCTION}

The most important critcrion for qualifying NIF first wall materials is the contamination rate of the final optics by target and ablation debris. The rate of debris shield contamination must be consistent with the refurbishment resources of the NIF. Specifically, current plans are to retrieve, clean, and rccoat the dcbris shiclds weekly, but refinish them only after 6 months. Sparse data suggest a limit for repetitive, dispersed metallic and refractory contamination-wi.e., thin films and particles less than $1 \mu \mathrm{m}$ (dust \& microsplats) - of about $1 \mu \mathrm{g} / \mathrm{cm}^{2}$ to allow a debris shicld to last one week at NIr fluences without excessive damage growth. For an average density of $10 \mathrm{~g} / \mathrm{cm}^{3}$, this corresponds to only $1 \mathrm{~nm}$. Since the debris shields sit approximately $6 \mathrm{~m}$ from the target chamber center, the maximum amount of mobile contamination (dircct and remobilized target debris plus material ablated from the chamber wall and its various protrusions) per laser shot is about 4.5 $\mathrm{g}$. This is equivalent to a $1 \mathrm{~nm}$ thickness over a $6 \mathrm{~m}$ sphere, even though the target chamber itself is only $5 \mathrm{~m}$ in diameter. Due to concerns about whether a $1 \mu \mathrm{g} / \mathrm{cm}^{2}$ contamination is truly acceptable, a $3 \mathrm{~g}$ budget has been adopted.

This limit is challenging indeed. The $x$-ray fluences in the target chamber will routinely be in the vicinity of $1 \mathrm{~J} / \mathrm{cm}^{2}$ on the chamber wall, with eventual exposures up to $\sim 2 \mathrm{~J} / \mathrm{cm}^{2}$ once ignition shots with yields of $10-20 \mathrm{MJ}$ are attained. ${ }^{1}$ Those fluences ablate 0.1 to $1.0 \mu \mathrm{m}$ of aluminum each shot, which is enough to turn the final optics into mirrors after a single shot. In a previous paper, we described $x$-ray experiments leading to the conclusion that $\mathrm{B}_{4} \mathrm{C}$ was the best material for limiting ablation of the first wall, as it provided the lowest ablation for a readily available commercial material. ${ }^{2}$ Even so, about 1 to $5 \mathrm{~nm}$ of material would be ablated over this fluence range. Laser damage experiments suggested that the final optics could tolerate 5-10 high fluence shots at the resulting $\mathrm{B}_{4} \mathrm{C}$ contamination level before substantial surface damage set it. 
It was recognized at the time that buildup of target debris would eventually defeat even the best first-wall material. ${ }^{3}$ Consequently, periodic $\mathrm{CO}_{2}$ pellet cleaning with a robot was envisioned. However, studies of cleaning efficiency indicated that a cleaning dwell time of $2-4 \mathrm{~s} / \mathrm{cm}$ would be required to clean half to two-thirds of the metallic target deposits from the first wall. For a $30 \mathrm{~cm}$ wide nozzle, this gives a cleaning rate of about $10 \mathrm{~cm}^{2} / \mathrm{s}$, which implies a target chamber cleaning time of about 80 hours. Given the limited cleaning effectiveness, high expense, and inefficiency of the capture shroud, inchamber $\mathrm{CO}_{2}$ pellet cleaning was discarded as impractical. Instead, the relative simplicity, cheapness, and effectiveness of ex-chamber bead blasting made it an attractive alternative. However, the panels would have to be removed from the chamber for this cleaning, and time limitations implied a cleaning frequency of no more than once every two months.

During the past year, we investigated the remobilization rate of Nova target debris from $\mathrm{B}_{4} \mathrm{C}$ in an attempt to determine whether the first-wall panels could be cleaned frequently enough by bead blasting to prevent an unacceptable level of target debris remobilization under NIF conditions. At the same time, we explored whether the outgassing level of plasmasprayed $\mathrm{B}_{4} \mathrm{C}$ could be reduced to a sufficient level, or whether hot-pressed $\mathrm{B}_{4} \mathrm{C}$ or a similar material could be reduced sufficiently in cost. We also explored whether passive cleaning of target contamination by capture on the rear of a louvered first wall could reduce or eliminate the need for active cleaning. A concurrent reevaluation of the neutron activation issues surrounding the use of steel in the target chamber came to the conclusion that a $\mathrm{Ni}$-free stainless steel would not be significantly worse in terms of occupational radiation exposure, so the ablation characteristics of stainless steel alloy 409 were evaluated as well. The combined result of these various efforts was that reablation of target debris from the first wall, not the first-wall itself, was the limiting factor of optics contamination, and that an inexpensive stainless-steel louvered first wall would be acceptable, at least for the initial years of NIF operation.

\section{IMPROVEMENTS IN $\mathrm{B}_{4} \mathrm{C}$}

In our earlier summary paper, ${ }^{3}$ we concluded that low-porosity, plasma-sprayed $\mathrm{B}_{4} \mathrm{C}$ would have acceptable outgassing characteristics for the NIF first wall. However, that conclusion was based on the assumption that the target chamber would be vented to dry air or nitrogen. Subsequent analysis concluded that the chamber would have to be a negative pressure with respect to the target bay during maintenance to prevent target chamber contamination from escaping to the target bay, so the chamber would likely see significant humidity. Therefore, the higher outgassing rate from atmospheric air would be more appropriate. In addition, the outgassing load from the final optics assembly was subsequently estimated to be substantially larger than originally thought, so a first-wall outgassing rate more typical of metals or hot-pressed $\mathrm{B}_{4} \mathrm{C}$ was desired. Despite some improvement in apparent porosity by metallography and despite attempts to reduce hydrophobic surface oxide by alcohol washing, no significant reduction of outgassing was attained. A single atlempt to fill the porosity with polymer increased rather than decreased the outgassing.

At the same time, reductions in the cost of hot-pressed $\mathrm{B}_{4} \mathrm{C}$ were pursued. Further chemical analysis of $\mathrm{B}_{4} \mathrm{C}$ from Norton found that previous high surfacc concentrations of carbon and silica were due to inadequate removal of the borondepleted surface layer formed during hot pressing. Cleaning with a harder abrasive solved that problem and opened the possibility of using their standard 1/8"-thick product. Ceradyne sought to reduce the machining costs of odd-shaped panels by modifying the $\mathrm{B}_{4} \mathrm{C}$. Cercom invented a process for making thinner hot-pressed $\mathrm{B}_{4} \mathrm{C}$. Finally, Greenleaf Corporation explored how to economically fabricate panels of heat-treated $A I-B_{4} C$ Cermet (a mixture of $B_{4} C, A_{B}$, and an alumino-boron carbide).

To get a better measure of the potential NIF lifetime of the current $B_{4} C$-based materials, $2.5 \times 5 \mathrm{~cm}$ samples were placed in the Nova target chamber at a distance of $44 \mathrm{~cm}$ from the targets for a total of 17 weeks. The samples were beadblasted, weighed and characterized by $x$-ray-fluorescence prior to the first 6 -week exposure. They were then removed and weighed and analyzed before and after beadblasting. The process was repeated after a 11-week exposure. Results of the test are given in Table 1. We conclude that all materials have acceptable $x$-ray ablation and shrapnel resistance. Especially after the second, longer exposure, any weight loss was less than the detection limit of $1 \mathrm{mg}$, after subtracting the weight gain due to target debris. A mass loss of $1 \mathrm{mg}$ over about 150 high-energy shots during the 11 week exposure corresponds to an ablation rate of $2 \mathrm{~nm} / \mathrm{shot}$. Given that the actual mass loss could be several times smaller, this is consistent with the result of $<1 \mathrm{~nm} / \mathrm{shot}$ reported earlier ${ }^{2}$ for a fluence of $1 \mathrm{~J} / \mathrm{cm}^{2}$. 
Table 1. Mass changes in mg during successive 6 and 11 week exposures of potential NIF first-wall materials.

\begin{tabular}{|c|c|c|c|c|c|c|c|c|}
\hline \multirow[b]{2}{*}{ Sample } & \multicolumn{4}{|c|}{ Initial 6 week exposure } & \multicolumn{4}{|c|}{ Subsequent 11 week exposure } \\
\hline & $\begin{array}{l}\text { total } \\
\Delta \text { mass } \\
(\mathrm{mg})\end{array}$ & $\begin{array}{l}\text { mass of } \\
\mathrm{Cu} \text { and } \\
\mathrm{Au}\end{array}$ & $\begin{array}{l}\text { net } \Delta \text { mass } \\
(\mathrm{mg})\end{array}$ & $\begin{array}{l}\Delta \text { mass } \\
\text { during } \\
\text { bead } \\
\text { blasting }\end{array}$ & $\begin{array}{l}\text { total } \\
\Delta \text { mass } \\
\text { (mg) }\end{array}$ & $\begin{array}{l}\text { mass of } \\
\mathrm{Cu} \text { and } \\
\mathrm{Au}\end{array}$ & $\begin{array}{l}\text { net } \\
\Delta \text { mass } \\
(\mathrm{mg})\end{array}$ & $\begin{array}{l}\Delta \text { mass } \\
\text { during bead } \\
\text { blasting }\end{array}$ \\
\hline $\mathrm{APS} 027^{\mathrm{a}}$ & 0.8 & 0.8 & 0.0 & 45.0 & 2.1 & 2.1 & 0.0 & 56.5 \\
\hline APS7958 ${ }^{b}$ & 0.2 & 0.8 & -0.6 & 49.6 & 1.6 & 1.6 & 0.0 & 36.5 \\
\hline $\mathrm{PR} 12^{\mathrm{c}}$ & 1.2 & 0.8 & 0.4 & 17.6 & 1.4 & 1.4 & 0.0 & N.A. \\
\hline $\mathrm{CEO} 22^{d}$ & 1.2 & 0.8 & 0.4 & 3.1 & 1.9 & 1.9 & 0.0 & 6.2 \\
\hline CEM08 ${ }^{\mathrm{e}}$ & 0.8 & 0.7 & 0.1 & 2.6 & 1.9 & 1.9 & 0.0 & 3.0 \\
\hline NOR $9^{f}$ & -1.1 & 1.4 & -2.5 & 6.9 & 1.4 & 1.4 & 0.1 & 6.4 \\
\hline CER6 $^{\mathrm{B}}$ & 1.5 & 0.6 & 0.9 & 6.4 & 1.6 & 1.6 & 0.1 & 7.9 \\
\hline CER $7^{\text {h }}$ & 0.9 & 0.9 & 0.0 & 11.9 & 1.1 & 1.1 & 0.0 & 27.3 \\
\hline $\begin{array}{l}\text { a. APS } \\
\text { b. Plas } \\
\text { c. Pro' } \\
\text { d. Cer }\end{array}$ & $\begin{array}{l}\text { asma-spra } \\
\text { filled APs } \\
\text { plasma-st } \\
\text { ne } 1 / 4 \text { " ho }\end{array}$ & $\begin{array}{l}\text { ed } \mathrm{B}_{4} \mathrm{C} \\
\text { plasma-sp } \\
\text { ayed } \mathrm{B}_{4} \mathrm{C} \\
\text { pressed } \mathrm{B}\end{array}$ & yed $\mathrm{B}_{4} \mathrm{C}$ & $\begin{array}{l}\text { c. } \\
\text { f. } \\
\text { g. } \\
\text { h. }\end{array}$ & $\begin{array}{l}\text { Modified } \\
\text { Norton } 1 / 8 \\
\text { Cercom } 1 / \\
\text { Greenleaf }\end{array}$ & $\begin{array}{l}\text { eradyne ho } \\
\text { "hot-press } \\
6 \text { " hot-prc } \\
\text { eat-treated }\end{array}$ & $\begin{array}{l}\text {-pressed } \mathrm{B}_{4} \\
\mathrm{~d} \mathrm{~B}_{4} \mathrm{C} \\
\mathrm{scd} \mathrm{B}_{4} \mathrm{C} \\
\mathrm{B}_{4} \mathrm{C}-\mathrm{Al} \text { cerr }\end{array}$ & \\
\hline
\end{tabular}

\section{ACCEPTABLE OPTICS CONTAMINATION RATES}

The target chamber material and geometric design depend critically on the maximum acceptable rate of contamination of the debris shields. NIF conceptual design set the maximum acceptable contamination rate of the debris shields at $1 \mathrm{~nm}$ or less average per shot based on $1 \%$ absorption for $0.2-0.5 \mathrm{~nm}$. However, the amount of absorption depends on the form of the deposits, i.e., whether they are truly thin films or fine particulate. Previous papers ${ }^{3,4}$ reported that thin films of $\mathrm{B}_{4} \mathrm{C}$ were more efficient at reducing the damage threshold of bare silica optics more efficiently than equivalent masses of $1-\mu \mathrm{m}$-sized dust, presumably because of the more effective energy absorption. In addition, laser pulses did seem effective at partially removing the dust particles prior to the onset of substantial damage. More recently, we found ${ }^{5}$ that metal films from 2 to $5 \mathrm{~nm}$ have a very detrimental effect on the damage threshold of the optics, but these thicknesses are far greater than would be acceptable from simple transmittance loss. At present there is insufficient data on both the nature of the NIF target chamber deposits and the relationship between small levels of the various deposits (composition and form) to determine whether $1 \mathrm{~nm}$ equivalent thickness is an acceptable debris shield contamination rate. Experiments are planned in which optics will undergo repetitive contamination between each probe laser pulse to closer simulate real conditions in the target chamber.

\section{REMOBILIZATION OF TARGET DEBRIS FROM $B_{4} \mathrm{C}$}

The required cleaning frequency depends critically on the rate of remobilization. In parallel to the pursuit of improved $\mathrm{B}_{4} \mathrm{C}$, we examined the ability of $\mathrm{x}$ rays to ablate various thin metal films deposited on $\mathrm{B}_{4} \mathrm{C}$ by a variety of techniques. The remobilization of metals have at least two plausible dependencies on thickness: (1) a threshold ablation thickness that is a function of $x$-ray fluence, at which point it increases with thickness by some functional form to the asymptotic limit of the pure metal, and (2) the ablated amount is proportional to the amount present. The first may be more appropriate for thin metal films, while the second is more appropriate for metal splats. Microscopic inspection of Nova deposits suggests that both forms of contamination are present.

Our first approach to understand this issue was expose sputtered metal films of varying thickness to Nova $x$ rays of varying fluence. ${ }^{6}$ Metals initially chosen were $\mathrm{Au}$, the conventional hohlraum material for indirect drive experiments, and $\mathrm{Ge}$, a vapor-pressure-equivalent surrogate for $\mathrm{Cu}$, used to shield targets from unconverted laser light. We concluded that sputtered films were much easier to remove than Nova-deposited films, apparently because their poor wetting and adhesion 
made them bead and spall from the surface upon mild $\left(<0.5 \mathrm{~J} / \mathrm{cm}^{2}\right) \mathrm{x}$-ray exposure. This is likely due either to the presence of wetting metals $\left(\mathrm{Cr}, \mathrm{Fe}, \mathrm{Co}\right.$ ) from real targets or implantation of $\sim 400 \mathrm{eV}$ Au ions a few angstroms into the $\mathrm{B}_{1} \mathrm{C}$.

Bombardment of sputtered Au deposits with $400 \mathrm{kV}$ carbon ions improved their adherence, but we ultimately concluded that a model of thin metal film remobilization was unattainable within our resources using this approach.

Instead, an experiment was conducted in which Nova debris was deposited on a $2.5 \times 5 \mathrm{~cm}$ coupon of $\mathrm{B}_{4} \mathrm{C}$ placed 35 $\mathrm{cm}$ from target center at angle relative to the target, and debris subsequently reablated was collected on the outside and inside of a metal box with an imaging slit over a period of 6 weeks $\left(93\right.$ shots) ${ }^{7}$. A schematic is shown in Figure 1. The material collected on the $\mathrm{B}_{4} \mathrm{C}$ was a combination of metal film and metal splats up to $1 \mathrm{~mm}$ in diameter. The material collected on the outside and inside of the stainless-steel secondary collector was a combination of a thin film largely composed of $\sim 50 \mathrm{~nm}$ particles or nodules and larger particles up to a few $\mu \mathrm{m}$ in diameter. Concentrations measured by $\mathrm{x}$-ray and electron-induced $\mathrm{x}$-ray fluorescence are given in Table 2. The amounts and distribution of metal deposit inside the box were consistent with an angular distribution of ablated material from the $\mathrm{B}_{4} \mathrm{C}$ corresponding to the $35^{\circ}$ FWHM Lorenzian angular distribution obtained in earlier experiments in which a $\mathrm{Au}$-coated $\mathrm{B}_{4} \mathrm{C}$ coupon and a stock $\mathrm{Al}$ coupon were irradiated with a narrow beam of $x$ radiation. ${ }^{8}$

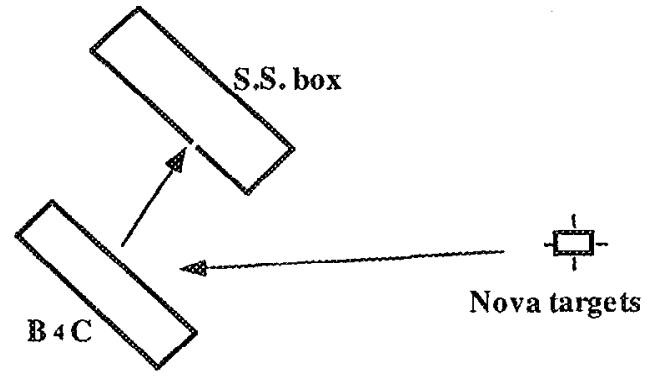

Figure 1. Schematic diagram of the intial louver reablation experiment. The $\mathrm{B}_{4} \mathrm{C}$ coupon was $\sim 35$ $\mathrm{cm}$ from target chamber center at an angle of $45^{\circ}$ relative to the ray from the target. The coupon was at an angle of $20^{\circ}$ relative to the hohlraum axis.

Table 2. Metal concentrations found on the primary and secondary collection surfaces on the initial louver reablation-capture experiment.

\begin{tabular}{lcccc}
\hline Sample & Technique & Material & $\begin{array}{c}\text { Areal density, } \\
\mu \mathrm{g} / \mathrm{cm}^{2}\end{array}$ & $\begin{array}{c}\text { Equiv. avg. } \\
\text { thickness, } \mathrm{nm}\end{array}$ \\
\hline $\mathrm{B}_{4} \mathrm{C}$ coupon & XXRF & $\mathrm{Cu}$ & 60 & 67 \\
& XXRF & $\mathrm{Au}$ & 6 & 3.1 \\
& EXRF & $\mathrm{Al}$ & $3-4$ & 12 \\
& EXRF & $\mathrm{Nb}$ & 8 & 9 \\
& EXRF & $\mathrm{Fe}$ & 30 & 38 \\
Outside of box & EXRF & $\mathrm{Cr}$ & 7 & 10 \\
facing $\mathrm{B}_{4} \mathrm{C}$ & $\mathrm{XXRF}$ & $\mathrm{Cu}$ & 17 & 19 \\
& $\mathrm{XXRF}$ & $\mathrm{Au}$ & 4.4 & 2.3 \\
& EXRF & $\mathrm{Al}$ & 3 & 10 \\
Inside box & EXRF & $\mathrm{Nb}$ & 8 & 9 \\
(max) & XXRF & $\mathrm{Cu}$ & 6.7 & 7.5 \\
& XXRF & $\mathrm{Au}$ & 1.8 & 0.9 \\
& EXRF & $\mathrm{Al}$ & 1.2 & 6.7 \\
\hline
\end{tabular}

Combining the angular distribution with the concentrations of various metals on the $\mathrm{B}_{4} \mathrm{C}$ and collector plates gives total mobilization factors of about $0.5,0.67,0.75$ and 0.70 for $\mathrm{Cu}, \mathrm{Au}, \mathrm{Nb}$, and $\mathrm{Al}$, respectively. This suggests that metal remobilization may be a significant source of contamination on the NIF, but a model is needed to account for the differences in circumstances between the Nova experiment and the NIF. Although the x-ray fluences are comparable, the metal loading and fate of the remobilized material are significantly different. The primary deposition rate onto the $\mathrm{B}_{4} \mathrm{C}$ for the Nova experiment is estimated to be about $4 \mu \mathrm{g} / \mathrm{cm}^{2}$ from the various final concentrations and geometric factors. NIF targets expect 
to generate about 1 gram of target debris spread over $314 \mathrm{~m}^{2}$, or $0.32 \mu \mathrm{g} / \mathrm{cm}^{2} / \mathrm{shot}, 12$ times lower than for our Nova experiment. Meanwhile, material remobilized on the NIF would deposit within reablation distance, while remobilized material on Nova disappears into an infinite sink.

The simplest model for this situation is to assume that the fraction of first-wall deposits remobilized is proportional to the amount present. This would be the case if the deposits were optically thick to the $\mathrm{x}$ rays and covered an increasing fraction of the area with increasing deposition, but it may hold for other circumstances as well.

In this case, the total fraction remobilized, $\mathrm{F}$, is given by

$$
\mathrm{F}=1-\left(1-\mathrm{e}^{-\mathrm{bct}}\right) / \mathrm{bct}
$$

where $t$ is the number of shots and $b$ is the fraction of the deposit that is mobilized for any given shot, and $c$ is the fraction that redeposits in a hidden location (sink). Likewise, the total contamination rate, or threat, $\mathrm{T}$, to the debris shield consists of material coming directly from the target and that reablated from the chamber wall according to the relation

$$
\mathrm{T}=\mathrm{a}\left(1+\left(1-\mathrm{e}^{-\mathrm{bct}}\right) / \mathrm{c}\right)
$$

where $\mathrm{a}$ is the amount of target debris coming directly from the target.

Setting $c=1$ and assuming 75 full-energy shots for the Nova experiment, $b$ ranges from 0.02 to 0.05 to achieve total remobilization fractions of 0.5 to 0.75 . If the fraction of material going to a sink on the NIF were only 0.1 , the minimum conceivable, the total threat to the debris shield would increase asymptotically to 11 times the direct threat $(1+1 / \mathrm{c})$ with a time constant of $\sim 300$ shots. However, the maximum tolerable increase in the total threat from the direct value is only 2 to 3 , as will be discussed later, so the total number of shots prior to cleaning would be only about 75, or less than one month of NIF operation. Since the maximum cleaning frequency for the envisioned robot system would be bimonthly, it appears that an active debris cleaning system is not feasible for the NIF. In contrast, if the fraction of material going to sink were increased to 0.9 , the asymptotic total threat would be only 2.1 times the direct threat, suggesting that an active cleaning system would not be needed.

\section{FEASIBILITY OF A STAINLESS STEEL LOUVER FIRST WALL}

While it is conceivable, albeit expensive, to fabricate a louvered first wall with $\mathrm{B}_{4} \mathrm{C}$, a combination of three factors-the projected difficulty and expense, the durability of stainless steel fixtures in the Nova chamber, and the possibility that target debris would quickly make the underlying first wall substrate material irrelevant-prompted us to reexamine the feasibility of using stainless steel (SS) as the first wall. This option had been rejected a few years earlier because of pcrccived problems with neutron activation.

A reconsidcration of neutron activation and disposal issues concluded that neither were a significant problem for the SS mass required to fabricate thin louvers. A plot of in-chamber dose rates as a function of cooldown time from various sources after 10 years of $1200 \mathrm{MJ} / \mathrm{year}$ opcration is given in Figure 2. The dominant contribution for the first 5 days is the Al vacuum chamber itself. No personnel access would be allowed during this time regardless of the composition of the first wall. After that time, a 316 SS first wall would become the major exposure source, but further analysis found that $90 \%$ of the problem is due to activation of $\mathrm{Ni}$. Nominally Ni-free alloys are available, with $\mathrm{Ni}$-levels less than $0.5 \mathrm{wt} \% .^{9}$ A similar analysis with $409 \mathrm{SS}$, including the $0.75 \mathrm{wt} \%$ of Ti required for welding compatability, reveals that the long-term radiation dose is only twice that from the aluminum chamber itself. However, this potential increased exposure would be largely eliminated by the reduced need for cleaning activated first-wall louvers compared to a flat $\mathrm{B}_{4} \mathrm{C} / \mathrm{Al}$ first wall. $\Lambda \mathrm{lso}$, the 409 SS first wall contributes negligibly for external doses during final optics maintenance. Finally, the decommissioning dose rate for stainless steel first wall panels is negligibly higher than for $\mathrm{B}_{4} \mathrm{C} / \mathrm{Al}$ panels, and waste disposal ratings $\left(>10^{-8}\right)$ are small enough to qualify as low level radioactive waste. 


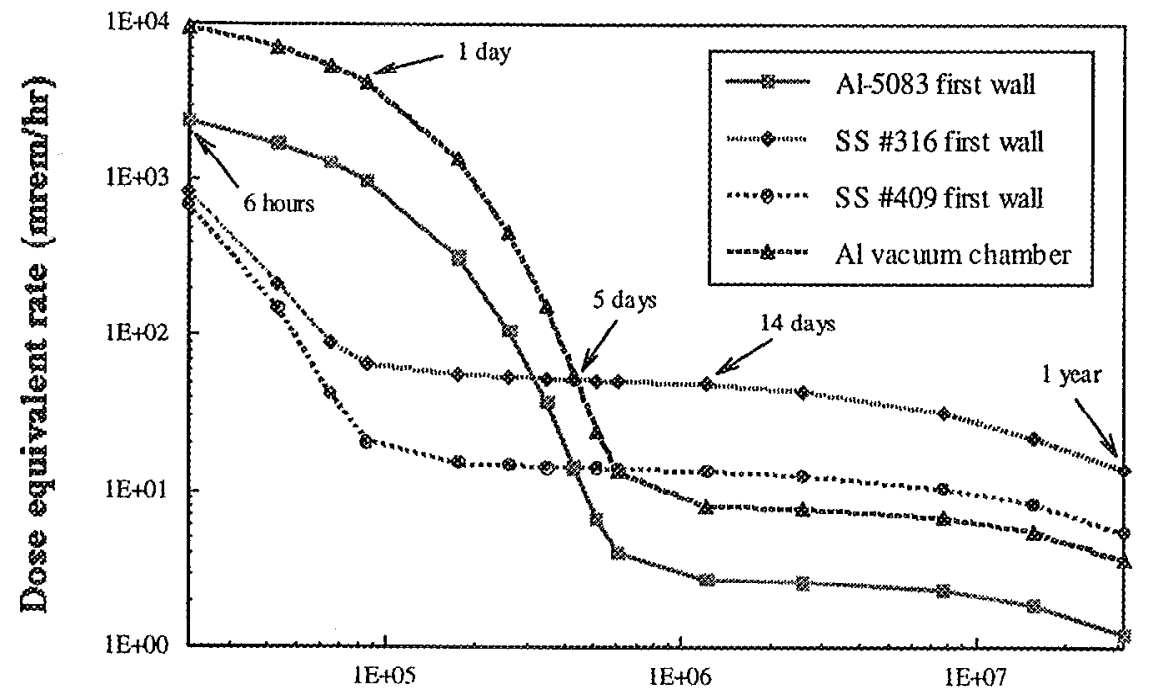

Figure 2. Personnel dose rate inside the target chamber after a $20 \mathrm{MJ}$ ignition shot following 10 years of $1200 \mathrm{MJ} / \mathrm{y}$ yields

Time after last shot (seconds)

Given that neutron activation is not a significant problem, two experiments were conducted to assess the ablation of 409 SS and overlying contaminants. The first experiment exposed polished coupons to 1 to 4 shots of varying fluence at normal incidence using the same technique as Anderson et al., ${ }^{2}$ and a second experiment compared the ablated material collected on Ti witness foils parallel to adjacent $409 \mathrm{SS}$ and $\mathrm{B}_{4} \mathrm{C}$ louvers (Fig. 3).

The ablation per shot versus fluence is shown in Figure 4 for $409 \mathrm{SS}, \mathrm{B}_{4} \mathrm{C}$, Al, and $\mathrm{SiO}_{2}$. As for other metals, the induced roughness due to surface melting of the SS was far greater than the removal thickness, but a two-dimensional scan of the surface by a WYCO white-light interferometer gave a removal depth with an estimated error of less than a factor of two. The ablated thickness of SS is far less than for $\mathrm{Al}$, comparable to that of $\mathrm{SiO}_{2}$, and approximately 10 times greater than $\mathrm{B}_{4} \mathrm{C}$. Given the possibility of a $90 \%$ capture efficiency for SS louvers (to be discussed later), the amount of SS potentially escaping into the target chamber and potentially contaminating optics is not much worse than for flat $\mathrm{B}_{4} \mathrm{C}$ panels.

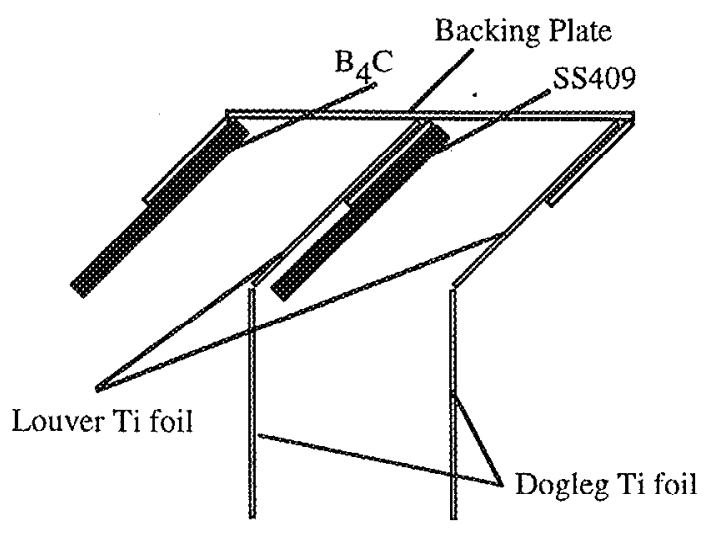

Figure 3. Schematic diagram of the comparative louver reablation-capture experiment. The center of the $\mathrm{B}_{4} \mathrm{C}$ and $\mathrm{SS}$ louvers was approximately $40 \mathrm{~cm}$ from target chamber center.

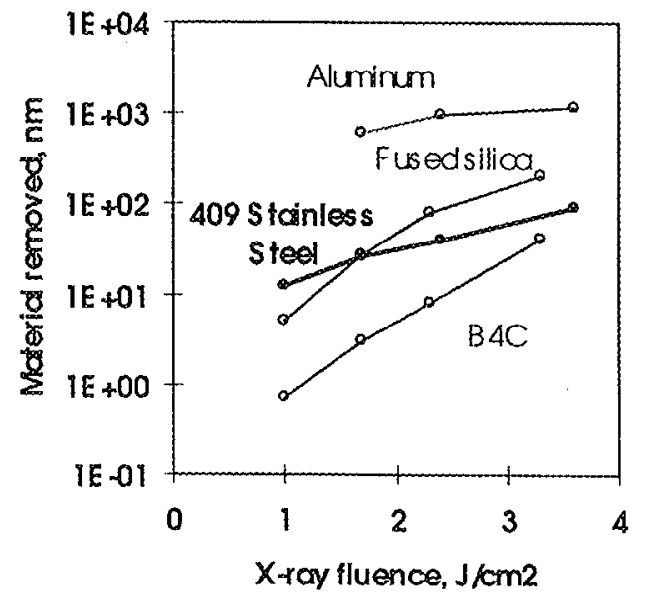

Figure 4. Thicknesses of 409 stainless steel ablated as a function of $\mathrm{x}$-ray fluence from a hohlraum emitting a ca. $200 \mathrm{eV}$ blackbody spectrum. 
The relative advantage of $\mathrm{B}_{4} \mathrm{C}$ decreased even more based on the results of the adjacent louver experiment. ${ }^{10}$ The ablation rates of $\mathrm{Fe}, \mathrm{Cu}$, and $\mathrm{Au}$ calculated from the amounts collected on the Ti foils are given in Table 3. The amount of $\mathrm{Fe}$ collected during the first week is consistent with that expected from the data in Figure 4. In subsequent weeks; the Fe ablation drops substantially. By the third week, there is little difference between the amount of Fe from the $\mathrm{B}_{4} \mathrm{C}$ or SS. A more detailed analysis indicates that the fraction of target debris remobilized per shot, $b$, increases from 0.03 for $\mathrm{B}_{4} \mathrm{C}$ to 0.06 for SS. Initially, therefore, $\mathrm{B}_{4} \mathrm{C}$ does have an advantage. However, the advantage diminishes with time as the target debris builds up on $\mathrm{B}_{4} \mathrm{C}$ according to the relation

$$
\alpha=\frac{1-e^{-b_{B} A C t}}{1-e^{-b_{S S} t}}
$$

Using the measured values of $b$, the relative debris shield contamination rate, $\alpha$, equals 0.9 after 90 shots, or 5 weeks on the NIF, for equivalent louver geometries.

Table 3. Deposition rates of target materials on witness foils used in the comparative louver reablation-capture experiment.

\begin{tabular}{ccccccccc}
\hline & \multicolumn{3}{c}{$\begin{array}{c}\text { Deposition rates on Ti foil } \\
\text { opposite } \mathrm{B}_{4} \mathrm{C}\left(\mu \mathrm{g} / \mathrm{cm}^{2} / \mathrm{shot}\right)\end{array}$} & \multicolumn{3}{c}{$\begin{array}{c}\text { Deposition rates on Ti foil } \\
\text { opposite SS409 }\left(\mu \mathrm{g} / \mathrm{cm}^{2} / \mathrm{shot}\right)\end{array}$} \\
\hline & shots & $\mathrm{Cu}$ & $\mathrm{Au}$ & $\mathrm{Fe}$ & $\mathrm{Cu}$ & $\mathrm{Au}$ & $\mathrm{Fe}$ \\
\hline Week 1 & 12 & 0.037 & 0.023 & 0.022 & 0.046 & 0.029 & 0.769 \\
Week 2 & 3 & 0.084 & 0.027 & 0.034 & 0.134 & 0.052 & 0.087 \\
Week 3 & 14 & 0.095 & 0.029 & 0.047 & 0.089 & 0.030 & 0.045 \\
Week 4 & 11 & 0.054 & 0.029 & 0.009 & 0.080 & 0.043 & 0.015 \\
\hline
\end{tabular}

\section{ESTABLISHING A CONTAMINATION BUDGET}

Using the provisional 1-nm-per-shot limit for debris shield contanination, a budget for contamination sources has been established. The source estimations can only be qualitative, since details of the targets are still unknown. At the chamber wall, 3 grams of metal with an average density of $10 \mathrm{~g} / \mathrm{cm}^{2}$, if evenly dispersed, would form an average deposition thickness of $1 \mathrm{~nm}$. However, the debris shields are recessed from the first wall in the final optics assembly (FOA) to a distance of $6.2 \mathrm{~m}$. If the material entering the FOA were deposited according to a $1 / \mathrm{r}^{2}$ law, as much as $4.5 \mathrm{~g}$ could be tolerated. However, given the concerns about whether the $1 \mathrm{~nm}$ limit is truly acceptable, a $3 \mathrm{~g}$ budget has been adopted.

Additional sources of contamination exist besides the direct and remobilized target debris. These sources include unconverted light beam dumps and ablation from the target positioner and diagnostic snouts. The laser targets themsclves will be irradiated with frequency tripled light, and the $40 \%$ of the total energy remaining as unconverted light must be absorbed either on target shields or on the far wall of the chamber. The former contamination source is considered part of the target, but the contribution from the wall is calculated assuming no credit for the shields.

One of the advantages of a louvered stainless steel first wall is that it also serves as an excellent beam dump. Experimental analysis of absorbing glass and $\mathrm{B}_{4} \mathrm{C}$ beam dumps showed that stainless steel generated the least amount of contamination of any option considered, as well as being the least expensive. ${ }^{11}$ Convolving the expected fluence distribution with the ablation versus fluence function gave a total ablation of $1 \mathrm{~g}$ of stainless steel. Since the planned louvers are calculated to have a $90 \%$ capture efficiency, ${ }^{10}$ only $0.1 \mathrm{~g}$ of this contribution need be considered.

The current design for the target positioner shield uses a disk of $\mathrm{B}_{4} \mathrm{C}$ covering a crushable $\mathrm{Al}$ foam. Because of the relatively small area of this shield, only 0.1-0.2 $\mathrm{g}$ of ablation is expected. Comparable amounts of ablation are expected from protruding diagnostics. Consequently, a budget of $0.3 \mathrm{~g}$ for these sources has been established.

Since the material ablated from the first wall by $200 \mathrm{eV} \times$ rays is almost completely remobilized target debris rather than substrate material for fluences of about $1 \mathrm{~J} / \mathrm{cm}^{2}$, and because the asymptotic limit of the direct plus remobilized target debris is 2.1 times the direct contribution for louvers with $90 \%$ capture efficiency, a target mass of $1 \mathrm{~g}$ would imply a total 
contamination source of $2.1 \mathrm{~g} / \mathrm{shot}$. Adding this to the other sources gives a total mobile contamination of $2.5 \mathrm{~g}$, less than the $3 \mathrm{~g}$ total budget.

There are two cautions concerning this analysis. First, it would imply that the mobile contamination would approach $0.4 \mathrm{~g}$ for infinitesimal targets. In fact, the ablation of the steel itself provides a lower limit of $0.5 \mathrm{~nm}$ for a Lambertian distribution of $\mathrm{x}$ rays having a maximum of $1 \mathrm{~J} / \mathrm{cm}^{2}$ at the target chamber poles, taking credit for a $90 \%$ louver capture efficiency. This also corresponds to $1.1 \mathrm{~g}$ of ablatant (give or take a factor of 1.5 depending on the assumed form for the ablation below $1 \mathrm{~J} / \mathrm{cm}^{2}$ ) from the chamber wall. Second, as the fluence increases, the $\mathrm{x}$-ray ablation increases as well, giving rise to a higher contamination rate. The true contamination rate is complicated by fact that these higher fluences caused by ignition will also include higher temperature $x$ rays, primarily in the $350 \mathrm{eV}$ range. ${ }^{\prime}$ A full discussion of this issue is beyond this paper, but as $\mathrm{x}$-ray energy increases, the relative advantage of $\mathrm{B}_{4} \mathrm{C}$ increases. Consequently, retrofit to $\mathrm{B}_{4} \mathrm{C}$ louvers may be required when ignition is attained. Monitoring using titanium sample coupons on the backs of selected louvers will provide historical data on debris and substrate mobilization rates and collection efficiency, to allow early detection of contamination trends that would warrant a first-wall retrofit.

Finally, the acceptability of a 1-nm-per-shot contamination rate has yet to be demonstrated. Unfortunately, it is extremely difficult, and maybe impossible, to select materials and cleaning procedures that can achieve lower contamination rates with an unprotected debris shield. Several ideas are being considered to reduce the contamination rate. First, a beam tube extending partially into the target chamber would reduce the viewfactor of the debris shield to contamination coming from the target chamber wall. This option will likely be installed on at least some beam ports during the early stages of the NIF to determine its effectiveness. A supplemental pulsed-gas purge though this tube may also be helpful at preventing slow-moving debris from reaching the debris shield. Alternatively, a thin, disposable debris shield of either glass or polymer could prevent all but the larger shrapnel from reaching the debris shield, ${ }^{12}$ but no material yet exists with adequate optical uniformity and $\mathrm{x}$-ray ablation characteristics. Finally, some type of electrical or magnetic capture device may reduce the particulates reaching the debris shield.

\section{REDUCING THE SHRAPNEL THREAT}

An earlicr paper ${ }^{13}$ presented the possibility that major damage to the first wall and final optics could come from shrapnel generated from unconverted light shine shields and from SS tubes transporting liquid He for cooling cryogenic targets. In fact, there is very little that can be done to protect final optics from shrapnel greater than $30 \mu \mathrm{m}$ or so. Such particles will easily penetrate a thin polymeric film and reach the debris shield. Instead, target designers must adopt a strategy of minimizing the amount of shrapnel generated and directing what is formed to the waist of the target chamber.

Figure 5 shows a cryogenic hohlraum design that substitutes conductive sapphire for He-filled SS for cooling. ${ }^{14}$ The distribution of damage on target chamber interior is shown in Figure 6. Most of the shrapnel damage occurs near the target chamber waist, indicating that this particular design is much more compatible with the NIF facility limitations. While this is not a final target design, it demonstrates what can be accomplished with an eye towards minimizing facility damage.

NIF will likely field a limited number of experiments that have large near-target surface areas with the potential to generate unacceptable debris ablation and shrapnel generation. Cryogenic frost and other materials have been explored to protect such large near-target surfaces, using geometries similar to a mini-chamber to surround the target. ${ }^{15}$ 


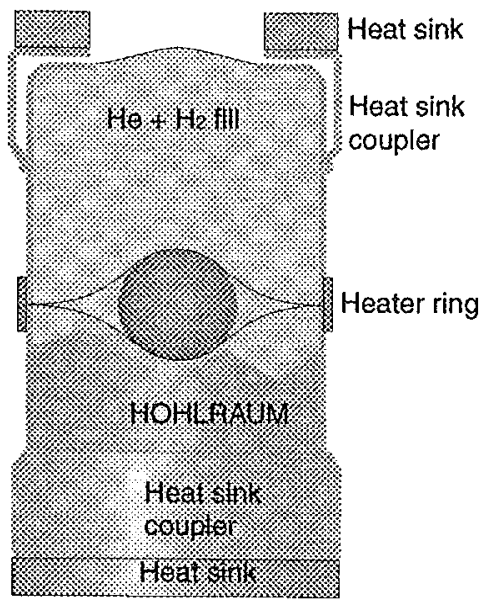

Figure 5. Schematic of a prototype cryogenic hohlraum design for the NIF used in shrapnel generation experiments.

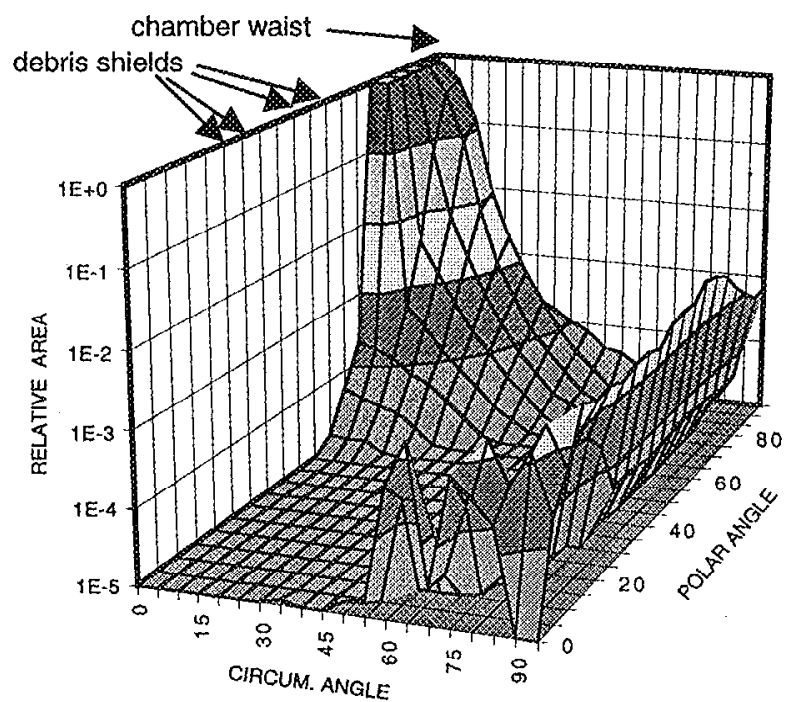

Figure 6. Areal distribution of the relative shrapnel damage on the first wall calculated from a $20 \mathrm{MJ}$ hohlraum ignition shot

\section{CONCLUSIONS}

Realistic projections of the amount of remobilized target debris for NIF conditions suggest that active target debris cleaning cannot be conducted often enough to prevent an unacceptably large contamination rate of the final optics debris shields. As a result, a louvered first wall with passive cleaning capability is necessary. The louvered design chosen for the NIF is a "dog-leg" configuration with an estimated capture efficiency of $90 \%$ for ablated material.

A secondary benefit of the passive cleaning approach is that the ablation resistance of the first wall material is less critical. Although stainless steel ablates about 10 times as much as $\mathrm{B}_{4} \mathrm{C}$ under NIF conditions, the ease of manufacturing highly efficient louvers largely eliminates the advantage of the $\mathrm{B}_{4} \mathrm{C}$. Furthermore, after a few tens of shots, the first wall ablation is dominated by remobilization of target debris from earlier shots, rather than mobilization of the substrate, making the underlying material less important.

Even with the NIF louver design, the contamination rate of the debris shield may exceed the acceptable limit, which is tentatively set at 1-nm-per-shot of absorbing film. As a result, supplemental methods may be required to reduce or eliminate the transport of remobilized target debris to the debris shield. None of these methods, however, can stop high velocity shrapnel from the target, so targets must be designed to vaporize nearly completely and so that any non-vaporized material turned into shrapnel is directed towards the target chamber waist.

\section{ACKNOWLEDGMENTS}

This work was performed under the auspices of the U. S. Department of Energy by Lawrence Livermore National Laboratory under Contract No. W-7405-ENG-48. We thank Leonard Summers for allow selection and supplying the 409 stainless steel, Jim Hughes for $\mathrm{x}$-ray fluorescence mcasurements, and the Nova technician staff for experimental support. 


\section{REFERENCES}

'A. T. Anderson, R. A. Managan, M. T. Tobin, and P. F. Peterson, "X-ray emission from National Ignition Facility indirect drive targets," Fusion Technology 30, 425-430 (1996).

${ }^{2}$ A. T. Anderson, A. K. Burnham, M. T. Tobin, and P. F. Peterson, "Modeling and experiments of National Ignition Facility first wall materials," Fusion Technology 30, 757-763 (1996).

${ }^{3}$ A. K. Burnham, M. T. Tobin, A. T. Anderson, E. C. Honea, K. M. Skulina, D. Milam, M. Evans, F. Rainer, M. Gerassimenko, "Development and Evaluation of First Wall Materials for the National Ignition Facility," Fusion Technology 30, 730-735 (1996).

${ }^{4}$ R. Rainer, A. Anderson, A. Burnham, D. Milam, and R. Turner, "Lifetime of contaminated target-chamber optics," LaserInduced Damage in Optical Materials: 1996, SPIE vol. 2966, 463-473 (1997).

${ }^{5}$ F. Y. Génin, A. M. Rubenchik, A. K. Burnham, M. D. Feit, J. Yoshiyama, A. Fornier, C. Cordillot, and D. Schirmann, "Thin film contamination effects on laser-induced damage of fused silica surfaces at $355 \mathrm{~nm}, " 3^{\text {td }}$ Annual International Conference on Solid State Lasers for Applications to Inertial Confinement Fusion, 1998.

${ }^{6}$ M. Gerassimenko, A. T. Anderson, and A. K. Burnham, "Studies of first wall deposit removal by exposure to x rays," Lawrence Livermore National Laboratory Report QDV-97-0005 (1997).

${ }^{7}$ M. Gerassimenko, A. K. Burnham, "Studies of first wall contamination and mobilization of contaminants," Lawrence Livermore National Laboratory Report QDV-97-0020 (1997).

${ }^{8}$ M. Gerassimenko, A. K. Burnham, "Studies of gold and aluminum mobilized by exposure to $\mathrm{x}$ rays," Lawrence Livermore National Laboratory Report QDV-97-0016 (1997).

${ }^{9}$ L. T. Summers, "Selection of Steel Allow for the First Wall of the NIF Target Chamber," Lawrence Livermore National Laboratory Technical Memorandum, October 16, 1997.

${ }^{10}$ J. M. Scott, P. F. Peterson, A. K. Burnham, Fusion Topical Meeting, ANS Summer Meeting, Nashville, Tennessee, June 811,1998

${ }^{11}$ P. K. Whitman, A. K. Burnham, M. Norton, F.Y. Genin, J. M. Scott, W. Hibbard, K. Bletzer, A. T. Anderson, S. Dixit, "Management of unconverted light for the National Ignition Facility target chamber," 3 th Annual International Conference on solid State Lasers for Applications to Inertial Confinement Fusion, 1998.

${ }^{12}$ P. Whitman, D. Milam, M. Norton, and W. Sell, "Loss of trasmittance in fluoropolymer films due to laser-induced damage at 1053 and $351 \mathrm{~nm}$," Laser-Induced Damage in Optical Materials: 1997, SPII Vol. 3244, 528-534 (1998).

${ }^{13}$ R. E. Tokheim, L. Seaman, T. Cooper, B. Lew, D. R. Curran, J. Sanchez, A. Anderson, M. Tobin, "Calculating the shrapnel generation and subsequent damage to tirst wall and optics components for the National Ignition Facility," Fusion Technology 20, 745-751 (1996).

${ }^{14}$ J. J. Sanchez and W. H. Giedt, "Thermal control of cryogenic cylindrical hohlraums for indirect-drive inertial confinement fusion," submitted to Applied Physics.

${ }^{15}$ P.F. Peterson and J.M. Scott, "Chamber-Protection Issues for Near-Target Experiments in NIF," Fusion Topical Meeting, ANS Summer Meeting, Nashville, Tennessee, June 8-11, 1998. 